\title{
Políticas e práticas inclusivas no ensino fundamental: das implicações nacionais às locais
}

\section{Inclusive policies and practices in fundamental teaching: from national to local implications}

\author{
Denise Meyrelles de Jesus ${ }^{1}$ \\ Alexandro Braga Vieira ${ }^{2}$
}

\begin{abstract}
RESUMO
A Constituição Federativa do Brasil de 1988, em seu art. 205, sinaliza que a Educação é um direito público e subjetivo, isto é, um direito de todos e um dever do Estado. A partir de então, muitos movimentos vêm sendo instituídos, em âmbito nacional e local, para que pessoas com deficiência, transtornos globais do desenvolvimento e altas habilidades/superdotação tenham as escolas de ensino comum como espaço-tempo de aquisição de conhecimentos. Esses movimentos vêm impulsionando os estados e os municípios brasileiros a instituírem políticas públicas, tanto para a formação de professores quanto para a reorganização das estruturas das unidades de ensino, dos currículos escolares e dos processos de avaliação, visando a garantir a esses alunos acesso, permanência e ensino nas escolas de educação básica. O presente texto busca problematizar como as legislações nacionais de Educação Especial vêm sendo assumidas pelos municípios do Estado do Espírito Santo, colocando em tela as tensões, os desafios e as possibilidades que atravessam esse processo.
\end{abstract}

Palavras-chave: educação especial; políticas públicas; políticas em ação.

${ }^{1}$ Bolsista CNPq - 2007-2010, Professora do Departamento de Educação, Políticas e Sociedade do Centro de Estudos do Programa de Pós-Graduação da Universidade Federal do Espírito Santos (DEPS-CE/PPGE-UFES) Brasil.

${ }^{2}$ Doutorando em Educação do Programa de Pós-Graduação da Universidade Federal do Espírito Santo (PPGE- UFES) Brasil. 


\begin{abstract}
The Brazilian Federal Constitution passed on 1988, in the article 205, points out that Education is a public and subjective right. That means an everybody's right and an obligation of the State. Since then, a big amount of movements have been instituted, in the national and local levels, for people who are disabled, have global developmental disorder and high abilities/ superendowment people to have ordinary learning schools as space-time of acquisition of knowledge. Those movements have been pushing forward the Brazilian states and municipalities to implement public policies, both for training of teachers and reorganization of structures of teaching unities, of scholarship curricula and evaluation processes aiming at the access, permanence and learning guarantee for this students at schools of basic education. The present paper seeks to problematize how national laws of Special Education have been assumed by municipalities of Espírito Santo State, presenting the tensions, challenges and possibilities that permeate this process.
\end{abstract}

Keywords: special education; public policies; policies in action.

\title{
Introdução: A educação especial no contexto nacional
}

É necessário construir uma utopia crítica que nos possibilite pensar em uma sociedade na qual a diferença humana não se transforme em desigualdade e que a exclusão seja substituída por processos de participação, pois temos o direito a sermos iguais sempre que a diferença nos inferioriza; temos o direito de sermos diferentes sempre que a igualdade nos descaracteriza (SANTOS, 2006).

O pensamento de Boaventura de Souza Santos (2006) expressa os pressupostos que fundamentam a escolarização de pessoas com deficiência, transtornos globais do desenvolvimento e altas habilidades/superdotação nas escolas de ensino comum, pois, com esse movimento, busca-se garantir que a diferença humana não seja assumida como sinônimo de desigualdade, que processos excludentes abram espaço para ações participativas e que se instituam propostas educacionais que valorizem as possibilidades de cada um e o desenvolvimento humano.

Neste artigo, focalizamos o contexto nacional no que tange às políticas de Educação Especial e suas implicações nos espaços locais, neste caso, o Estado do Espírito Santo. 
Tomando o contexto recente das "normatizações" legais, observa-se que a Constituição Federativa do Brasil de 1988, em seu art. 205, já sinaliza que a educação é um direito de todos e um dever do Estado e da família, devendo ser promovida e incentivada com a colaboração da sociedade, visando ao pleno desenvolvimento da pessoa, seu preparo para o exercício da cidadania e sua qualificação para o trabalho (BRASIL, 1988). Com esse pressuposto legal, a escolarização de alunos que apresentam algum tipo de comprometimento mental, físico ou psíquico, que por muito tempo foi realizada em instituições de ensino especializado, passou, também, a ser promovida pela escola, assumida como um espaço para todos. Para o contexto dessas escolas, inscreveu-se o princípio das escolas inclusivas, ou seja, que todas as pessoas com as mais diferentes histórias de vida e condições de existência possam aprender juntas.

Vale ressaltar que o fato de pensarmos esses cotidianos como espaços inclusivos foi impulsionado por ações internacionais ${ }^{3}$, como a Declaração Mundial de Educação para Todos, de 1990, e a Declaração de Salamanca, de 1994, que conclamaram a necessidade de instituição de políticas públicas educacionais voltadas para que a diferença humana fosse assumida como mais uma peça do ato educativo.

Esse movimento internacional influencia a elaboração da Lei de Diretrizes e Bases da Educação Nacional (LDB n. ${ }^{\circ}$ 9.394/96, de 20 dez. 1996), que garante o direito de esses alunos estudarem na escola regular, recebendo atendimento educacional especializado para atender às suas necessidades de aprendizagem sempre que necessário.

Após cinco anos da LDB de 1996, novas diretrizes são apontadas para a escolarização desses alunos, pois, com a Resolução n. ${ }^{\circ}$ 2, de 11 set. 2001, são instituídas as Diretrizes Nacionais da Educação Especial na Educação Básica. Dentre as orientações presentes no documento, destacamos: a) convoca os siste-

\footnotetext{
${ }^{3}$ Esses movimentos merecem ser pensados em sua complexidade, pois, ao passo que trouxeram perspectivas de expansão do ensino para as minorias sociais, trouxeram, também, implícitos os interesses das agências de fomento - em especial as do Banco. Vale ressaltar que o Banco Mundial tem sido um ator importante no cenário da política educacional dos anos 90, no Brasil, considerando a Educação como um instrumento fundamental para promover o desenvolvimento econômico e a redução da pobreza, principalmente nos países subdesenvolvidos. Nesse sentido, verifica-se que no Brasil vários pacotes de reformas educativas foram propostos pelo Banco Mundial, podendo ser destacads: a prioridade sobre a Educação Básica; a melhoria da qualidade (e eficiência) da educação como reforma educativa; a prioridade sobre os aspectos financeiros e administrativos da reforma educativa - propondo: reestruturação orgânica dos ministérios, das instituições intermediárias e das escolas, fortalecimento dos sistemas de educação e capacidade de pessoal em assuntos administrativos - e, por último, descentralização e instituições escolares autônomas e responsáveis por seus resultados (TORRES, 1998).
} 
mas de ensino a fazer funcionar um setor de Educação Especial para a instituição de políticas públicas inclusivas; b) define a população de estudantes a ser apoiada por essa modalidade de ensino ${ }^{4}$; c) assume as escolas de ensino comum como espaço-tempo de aprendizagem dos alunos; d) garante a participação desses sujeitos nas propostas curriculares das escolas, reafirmando a necessidade de elas serem reorganizadas de forma mais flexível; e) apresenta professores de sala de aula capacitados e apoiados por especialistas em Educação Especial para desenvolvimento de ações colaborativas.

Dessa forma, tanto os estados quando os municípios brasileiros foram convocados a materializar essas diretrizes legais em políticas públicas educacionais, visando à garantia do direito de esses alunos estudarem, já que as marcas de sua diferença não poderiam impossibilitá-los de assumir a identidade de alunos. Nos anos de 2008 e 2009, novas diretrizes são apontadas para a escolarização desses sujeitos. É desencadeado um processo, coordenado pela Secretaria de Educação Especial do Ministério da Educação, envolvendo pesquisadores e profissionais da área da Educação Especial para a elaboração do documento "Política Nacional de Educação Especial em Uma Perspectiva Inclusiva". Tal documento traz novas orientações para a área, aqui evidenciada uma nova definição dos sujeitos ${ }^{5}$ contemplados pelas políticas de Educação Especial e encaminhamentos para a oferta de atendimento educacional especializado (BRASIL, 2008).

Os movimentos iniciados pelo documento aqui referido ganham maiores definições com o Decreto n. ${ }^{\circ} 6571 / 2008$, de 17 set. 2008, que dispõe sobre a oferta de atendimento educacional especializado, e a Resolução n. ${ }^{\circ} 4 / 2009$, de 2 nov. 2009, que institui as diretrizes operacionais para o desenvolvimento desse

${ }^{4}$ Pautada na Declaração de Salamanca de 1994, a Resolução CNE/CEB n. ${ }^{\circ}$ 2, de 11 set. 2001, definia, como sujeitos a serem atendidos pela Educação Especial, os que, durante o processo educacional, apresentassem: I - dificuldades acentuadas de aprendizagem ou limitações no processo de desenvolvimento que dificultem o acompanhamento das atividades curriculares, compreendidas em dois grupos: a) aquelas não vinculadas a uma causa orgânica específica; b) aquelas relacionadas com as condições, disfunções, limitações ou deficiências; II - dificuldades de comunicação e sinalização diferenciadas dos demais alunos, demandando a utilização de linguagens e códigos aplicáveis; III - altas habilidades/superdotação, grande facilidade de aprendizagem que os leve a dominar rapidamente conceitos, procedimentos e atitudes (BRASIL, 2001, art. $4^{\circ}$ ).

${ }^{5}$ Alunos com deficiência: aqueles que têm impedimentos de longo prazo de natureza física, intelectual, mental ou sensorial. Alunos com transtornos globais do desenvolvimento: aqueles que apresentam um quadro de alterações no desenvolvimento neuropsicomotor, comprometimento nas relações sociais, na comunicação ou estereotipias motoras. Incluem-se nessa definição alunos com autismo clássico, síndrome de Asperger, síndrome de Rett, transtorno desintegrativo da infância (psicoses) e transtornos invasivos sem outra especificação. Alunos com altas habilidades/superdotação: aqueles que apresentam um potencial elevado e grande envolvimento com as áreas do conhecimento humano, isoladas ou combinadas: intelectual, liderança, psicomotora, artes e criatividade. 
tipo de trabalho. Esses documentos evidenciam a definição de atendimento educacional especializado assumida pelo Ministério da Educação, ou seja, um “[...] conjunto de atividades, recursos de acessibilidade e pedagógicos organizados institucionalmente, prestado de forma complementar ou suplementar à formação desses alunos no ensino regular" (BRASIL, 2008, art. $1^{\circ}$ ), ofertados no contraturno de matrícula dos alunos, em centros especializados ou em salas de recursos multifuncionais instaladas nas escolas de ensino comum. Tais trabalhos não podem ser substitutivos ao processo educacional desencadeado em salas de aula comuns e devem estar contemplados na proposta pedagógica da escola de origem dos alunos. Além de apresentar o que o Ministério da Educação vem adotando como política de atendimento educacional especializado, reforça quem são os sujeitos contemplados por essas ações, sujeitos esses já anunciados na Política Nacional de Educação Especial em uma perspectiva inclusiva de 2008.

Dessa forma, observamos que novos direcionamentos vêm sendo dados para a escolarização desses alunos, que se materializará nas salas de aula das escolas de ensino comum e na oferta de atendimentos educacionais especializados. Esses movimentos levam o grupo de pesquisa "Políticas de Inclusão Escolar, Formação e Práticas Pedagógicas", da Universidade Federal do Espírito Santo, a desenvolver o estudo "Políticas de Educação, Inclusão Escolar e Diversidade pelo olhar daqueles que as praticam: por diferentes trilhas", que objetivou cartografar o movimento de inclusão escolar no Estado do Espírito Santo a partir do questionamento: como os municípios capixabas vêm colocando em ação as diretrizes legais instituídas nacionalmente para a Educação Especial em uma abordagem inclusiva?

Nosso olhar buscou entender os dispositivos instituídos pelos municípios para a escolarização desses alunos, isto é, as possibilidades de atendimentos oferecidas; como os municípios capixabas definiam os sujeitos contemplados pelas políticas de Educação Especial; a relação entre as escolas de ensino comum e instituições especializadas e os apoios destinados ao processo de aprendizagem dos alunos.

Procuramos, no estudo, evidenciar pistas, sinais e indícios que nos levassem a perceber movimentos, bem como os desafios. Buscamos criar o que Santos (2007a) entende por ecologia de saberes, ou seja, uma articulação de conhecimentos, práticas, ações e movimentos que juntos podem favorecer a constituição de uma sociedade melhor e mais justa, e, principalmente, de uma escola na qual caiba a diferença humana, pois consideramos que

[...] o simples acesso à escola é condição necessária, mas não suficiente para tirar das sombras do esquecimento social milhões de pessoas cuja 
existência só é reconhecida nos quadros estatísticos e que o processo de exclusão educacional não se dá mais principalmente na questão do acesso à escola, mas sim dentro dela (SADER, 2005, p. 16).

Assim, o estudo buscou cartografar movimentos, mas também instituir novas/outras possibilidades de ação para falarmos em escolas com propostas inclusivas, que, nas palavras de Ainscow (2009, p. 21), é “[...] um processo de transformação de valores em ação, resultando em práticas e serviços educacionais, em sistemas e estruturas que incorporam [...] valores comprometidos com o desenvolvimento humano".

Cientes de que a constituição dessas propostas será efetivada em uma sociedade fundamentada em princípios excludentes, procuramos, também, criar novas linhas de pensamento e de ação pela via de diálogos reflexivo-críticos entre gestores educacionais, pedagogos, professores, profissionais em atuação em instituições especializadas para a promoção de possíveis encaminhamentos gerados por essa dinâmica social que exclui, segrega e faz a negação de direitos, uma vez que, como nos alerta Santos (2006, p. 134), “[...] confrontamo-nos com problemas modernos para os quais não temos soluções modernas".

\section{O desenho metodológico: cartografando em busca de pequenos ou grandes sinais/indícios}

Para a cartografia dessas políticas em ação, reunimos profissionais em atuação nas Secretarias Municipais, Superintendências Regionais de Educação $^{6}$, instituições especializadas e escolas de ensino comum. A pesquisa foi desenvolvida no transcorrer dos anos de 2007 a 2009, por meio de um diálogo reflexivo-crítico sobre as políticas públicas instituídas em cada um dos $78 \mathrm{mu}-$ nicípios que compõem o Estado do Espírito Santo.

Reunimos os participantes do estudo nas sedes das 11 Superintendências Regionais de Educação (SRE). Cada município foi convidado a participar do encontro realizado na SRE de sua área de jurisdição. No ano de 2007, organizamos um primeiro ciclo de encontros, cujo objetivo foi conhecer os trabalhos de Educação Especial na perspectiva da inclusão escolar no estado e apresentar

\footnotetext{
${ }^{6}$ Forma de organização da Rede Estadual de Ensino do Estado do Espírito Santo.
} 
dados censitários encaminhados pelas escolas/secretarias municipais e estaduais de educação ao Ministério da Educação. Percebemos, nesses primeiros encontros, que os dados constantes no MEC não retratavam a realidade presente nas redes de ensino ali representadas. Tal iniciativa culminou na realização do I Colóquio, intitulado "Pesquisa de Políticas Públicas em Educação Especial/ Inclusão Escolar no Espírito Santo: constituindo bases teórico-metodológicas", realizado em maio de 2008, na UFES (Universidade Federal do Espírito Santo), envolvendo 150 profissionais.

No período de 2008/2009, realizamos um segundo ciclo de diálogos, visando a promover uma retomada/balanço das ações até então realizadas, principalmente após o I Colóquio. Neste segundo ciclo, "desafiamos" os participantes a pensar: Quais são as políticas de Educação Especial instituídas em seus municípios? Quais os dispositivos de atendimento? Quem são os alunos da Educação Especial?

Nossa intenção era fomentar oportunidades para que os profissionais envolvidos no estudo vivessem um processo denominado por Santos (2006) de tradução, ou seja, um espaço no qual as diferentes experiências, expectativas, movimentos e conhecimentos pudessem se encontrar e dialogar criando novas possibilidades de atuação e de transformação do contexto social. Nas palavras de Santos (2007a, p. 39-41), tradução

[...] é um processo pelo qual vamos criando e dando sentido a um mundo que não tem realmente um sentido único [...]. É um processo distinto [...] para criar uma nova concepção de dignidade humana e de consciência humana [...]. É preciso criar inteligibilidade sem destruir a diversidade.

Esse conjunto de informações deu subsídio para a implementação do "2 ${ }^{\circ}$ Colóquio de Pesquisa em Educação Especial/Inclusão Escolar: dialogando com as produções das Superintendências e dos Municípios", realizado em maio de 2009, que buscou refletir e apresentar as ações implementadas pelos municípios capixabas, visando à garantia de escolarização de alunos com deficiência, transtornos globais do desenvolvimento e altas habilidades/superdotação. Esse processo possibilitou aos pesquisadores acompanhar os movimentos instituintes vividos no Estado do Espírito Santo. 


\section{Da legislação às políticas em ação}

Focalizaremos, nesse texto, duas questões que apareceram como maior evidência no estudo: a) os sujeitos contemplados por essas políticas; b) os dispositivos de atendimento. Trata-se de aspectos que necessitam ser tensionados em conjunto, visto que aparecem, via de regra, associados pelos participantes do estudo.

a) Os sujeitos contemplados pelas políticas de Educação Especial no Estado do Espírito Santo

Dentre os objetivos traçados para o desenvolvimento da pesquisa, interessava ao grupo sistematizador do estudo identificar "quem são os sujeitos" dessa modalidade de educação ou da perspectiva de inclusão. Essa mesma abordagem vinha sendo analisada por outros autores (BAPTISTA, 2003; JESUS, 2002; PIETRO, 2004), pois essa pergunta, conforme salienta Baptista (2003, p. 50), "[...] é de difícil resposta mesmo para os profissionais da área visto que houve um alargamento desse grupo de sujeitos, acompanhando o avanço de formas mais recentes de conceitualização, como o conceito de necessidades educativas especiais".

Nossas análises evidenciaram que a "deficiência intelectual" é a categoria mais presente. Em nosso estudo, a categoria se apresenta em todas as regiões. Ao tomarmos a categoria "condutas típicas" (conforme indicava o antigo modelo censitário utilizado pelo MEC), observamos que quase $50 \%$ das regiões identificam esses sujeitos como um público potencial.

A categoria "deficiência auditiva" aparece contemplada em 100\% das SREs. Em contrapartida, em relação à "surdez", apenas $60 \%$ delas afirmam que têm alunos surdos assistidos em seus processos educativos. Esse dado nos levaria a pensar sobre uma postura teórica que ora nos falava de surdez, ora de "deficiência auditiva".

A "surdo-cegueira" se presentifica em apenas $10 \%$ do conjunto das regiões e a categorização de "deficiência múltipla" foi indicada por cerca de $50 \%$ da totalidade das regiões. Talvez possamos afirmar com isso que os alunos não chegaram às escolas ou estão ainda "segregados". Quanto à "deficiência física", quatro SREs não mencionam essa categoria como sujeitos atendidos. Precisamos chamar a atenção para esse dado, visto que apenas 30\% das regiões que compõem esta pesquisa sinalizam para esses sujeitos. O "autismo" se evidencia em $64 \%$ das regiões. 
É importante destacar que, do conjunto das regiões, cerca de 50\% acrescentam que o seu público potencial é composto por crianças/adolescentes em situação de "dificuldade de aprendizagem" (sinalizam para os déficits de atenção, transtorno do déficit de atenção, hiperatividade, entre outras).

Dialogando com os dados relacionados com o segundo ciclo da pesquisa, em resposta à questão: "Quem são os sujeitos da Educação Especial/inclusão escolar?”, as análises ganham contornos qualitativos. É possível visualizar a dificuldade de identificação dos sujeitos pelos profissionais que estão envolvidos diretamente com as ações das Secretarias de Educação (Educação Especial/inclusão escolar). Outra discussão presente em praticamente todos os espaços foi a dificuldade de identificação dos sujeitos, atribuída à ausência de "laudo médico".

Aqueles que conseguem entrar na escola podem tornar-se motivo de intranquilidade para seus professores, sendo subjetivados como os "desacreditados" (SILVA; FREITAS, 2006). Cria-se, assim, um interdito:

Não temos laudo e, isso fica difícil de trabalhar. Não sabemos qual é o tipo de deficiência do aluno, ou que tipo de síndrome ele tem. É muito difícil chegar para a gente um aluno com laudo para a gente poder trabalhar com o aluno (REPRESENTANTE DA SRE "Y").

Padilha (1997, p. 9) argumenta que

[...] as características interpretadas como distúrbios, patologias, incapacidades para aprender e para se adaptar ao meio escolar são consideradas como problemas unicamente do indivíduo. Os desvios estão nele. Tal concepção está marcada tanto na prática pedagógica de sala de aula [...] como na legislação que estabelece os subsídios para organização e funcionamento de serviços de educação especial, na área da deficiência mental.

Surgem novas possibilidades de ampliarmos o diálogo para além de identificar os sujeitos. Parece-nos importante compreender quais alternativas de atendimento temos construído para responder às necessidades educacionais especiais demandadas por esses alunos. 


\section{b) Os dispositivos de atendimento}

A segunda questão evidenciada no estudo foi identificar os dispositivos de atendimento instituídos para a escolarização desses alunos. Os profissionais envolvidos na pesquisa nos falam que há movimentos voltados para a inclusão desses sujeitos nas escolas de ensino comum a partir de diferentes dispositivos.

O primeiro a ser evidenciado fala sobre a preocupação em garantir o direito da matrícula desses sujeitos nas escolas de ensino comum.

[...] na rede municipal tem muitos surdos [...]. O professor não sabe nem falar bom-dia em LIBRAS [...]. Nós contratamos as pessoas para fazer esse atendimento [...]. Eles estão na sala junto com o professor [...]. Eles foram contratados para [...] está fazendo essa ponte com os alunos. Nós estamos conseguindo ensinar aos alunos LIBRAS porque eles não sabiam e estamos começando a alfabetizar (REPRESENTANTE DA REDE MUNICIPAL “H”).

No estado há uma pluralidade de espaços significados como salas de recursos/apoio. Em um mesmo município ou até em uma mesma escola, há alunos que somente são atendidos nesses espaços, alguns têm suas especificidades trabalhadas no contraturno, outros fazem uma dobradinha entre a sala de aula e a sala de recursos. Muitas vezes, a necessidade e/ou condição do aluno é que determina como ele será atendido na escola. "[...] trabalhamos atualmente na rede municipal com as salas de apoio para atender os alunos das séries iniciais de $1^{\mathrm{a}}$ à $4^{\mathrm{a}}$ série, em turnos alternados" (REPRESENTANTE DA REDE MUNICIPAL "W").

Contamos, também, com o trabalho de professores itinerantes. Esses profissionais, geralmente, percorrem várias escolas "levando trabalhos especializados". Como esse trabalho é realizado no contexto da escola? Em alguns casos em sala de aula, outros na sala de recursos, no horário de aula, no contraturno, bem como em espaços "improvisados" pela escola: “[...] nós temos professores itinerantes de manhã [...] e um itinerante à tarde. [...] Os alunos ficam dentro da sala de aula" (REPRESENTANTE DA REDE ESTADUAL - MUNICÍPIO “Z”).

Outra realidade observada é a contratação de estagiários para acompanhamento dos trabalhos desenvolvidos com os alunos que apresentam necessidades educacionais especiais. Muitas vezes, esses futuros educadores, ainda em processo de formação, acabam por se responsabilizar pelo atendimento educacional desses sujeitos, principalmente quando efetivada a matrícula de alunos com maiores comprometimentos. 
[...] este ano eu consegui algumas estagiárias. Vinte e cinco para estar dando um apoio pedagógico, principalmente com as crianças com NEE porque eu não consegui professor de apoio [...]. A escola acaba vendo as estagiárias como especialistas [...] (REPRESENTANTE DA REDE MUNICIPAL "F").

Há também a instalação de salas de recursos multifuncionais nas escolas de ensino comum, criadas mediante o recebimento de recursos financeiros e pedagógicos para oferta de atendimento educacional especializado, conforme estabelecido pelo Decreto 6.571, de 11 set. 2008. “[...] na rede municipal nós temos também as salas [...] multifuncionais [...]. Ano passado era só uma. Agora nós temos quatro [...]. São sete professores que trabalham nesse espaço" (REPRESENTANTE DA REDE MUNICIPAL “S”).

A falta de apoio especializado na escola comum também se configura em dispositivo, pois alguns municípios sinalizam que é efetivada a matrícula de alunos com deficiência sem apoio específico. Os professores de sala de aula são os sujeitos que buscam diversificar as atividades para esses alunos:

[...] no momento [...], as salas são regulares, nós não fazemos esse atendimento especializado, nem na rede municipal e nem na rede estadual [...]. Nós temos alunos com necessidades especiais e deficiência tanto na zona rural quanto na zona urbana (REPRESENTANTE DA REDE ESTADUAL - MUNICÍPIO “P”).

Outra forma de atendimento são os serviços prestados por instituições especializadas que ora dividem os atendimentos com a escola de ensino comum, ora se configuram como a única política de atendimento (principalmente para os alunos com maiores comprometimentos).

[...] A Secretaria de Educação lá é a favor da integração. Já tem uma escola que é a Pestalozzi, excelente, não precisa estar se preocupando com isso, porque os alunos já fazem a integração na Pestalozzi [...]. A Pestalozzi é uma escola em nível de primeiro mundo [...] (REPRESENTANTE DA REDE MUNICIPAL “X”). 
Podemos perceber que há movimentos para que o trabalho pedagógico seja realizado em sala de aula, mas, predominantemente, o atendimento educacional dos alunos é "lembrado" como se realizando em espaços fora da sala de aula comum, mesmo nos casos em que ocorre no contexto da escola. Cabe ressaltar que, para além dos trabalhos pedagógicos, também há a forte presença de atendimentos clínicos e terapêuticos, pela via de parcerias entre a Prefeitura Municipal e as instituições especializadas, significados como práticas educacionais: "Os [...] pedagogos fazem o encaminhamento para o psicólogo e para o fonoaudiólogo [...] que fazem o atendimento em horário alternado [...]" (REPRESENTANTE DA REDE MUNICIPAL “G”).

Embora as políticas locais apontem para a educação escolar como direito de todos os alunos, são observados arranjos educacionais de atendimento que parecem se apoiar "nas faltas" e a classe comum ainda se constitui um espaço de acesso seletivo (JESUS, 2005; PRIETO, 2009).

Assim, cabe aos sistemas de ensino se reorganizar para atender às necessidades que os alunos trazem para o contexto escolar. Há que se pensar cotidianamente como trabalhar com as diferenças humanas. Parece-nos que o caminho a ser percorrido é ainda longo, mas podemos dizer que há movimentos e que o Estado do Espírito Santo é um mosaico com diferentes formas de atendimento (JESUS, 2008).

\section{Considerações finais}

O objetivo do estudo foi compreender como os municípios capixabas vêm instituindo políticas públicas de Educação Especial/Inclusão Escolar, a partir das diretrizes legais que acenam para a área em tela. Para tanto, propusemo-nos a cartografar esses movimentos, bem como os desafios que aparecem no transcorrer dessa caminhada.

Vemos que as diretrizes legais vêm impulsionando as redes de ensino a criarem movimentos, tanto para a definição dos sujeitos a serem contemplados pela modalidade de Educação Especial quanto para a instituição de dispositivos para a escolarização desses alunos.

Fica claro que essa "escolarização" vem se dando nas escolas de ensino comum e nas instituições especializadas.

Observamos, conforme nos indicam Caiado e Laplane (2009), um quadro contraditório em relação à política de inclusão escolar, com o fortalecimento de instituições especializadas e das funções que estas têm desempenhado, ou seja, "[...] uma trama complexa entre o público e o privado". 
No estado, desafios emergem a todo o instante, mas a preocupação de se fazer garantir a educação como um direito de todos é uma situação que não pode ser negada. Como fazer uma escola para todos? Tal questionamento nos faz recordar Santos (2008, p. 13), quando diz: “[...] vivemos um tempo de perguntas fortes e de respostas fracas". Mesmo que ainda convivamos com respostas fracas para tal questão, podemos perceber que o Estado do Espírito Santo vem buscando outras possibilidades de ação para que tal resposta se fortaleça e faça das escolas de ensino comum um espaço de todos.

Acreditamos, conforme Santos (2007b), que, quando as ações locais são vizibilizadas, fazem suas "existências". De acordo com o autor, a academia precisa instituir ações que garantam que as produções de espaços remotos se façam presentes. Há que se valorizar, dialogar, trocar, contagiar-se com o agir do centro.

\section{REFERÊNCIAS}

AINSCOW, Mel. Tornar a escola inclusiva: como essa tarefa deve ser conceituada? In: FÁVERO, Osmar et al. (Org.). Tornar a educação inclusiva. Brasília: UNESCO, 2009. p. 11-23.

BAPTISTA, C. R. Sobre as diferenças e as desvantagens: fala-se de qual educação especial? In: MARASCHIN, C. (Org.). Psicologia e educação: multiversos sentidos, olhares e experiências. Porto Alegre: UFRGS, 2003.

BRASIL. Resolução CNE/CEB n. 2. Institui diretrizes nacionais para a educação especial da educação básica. Diário Oficial [da] República Federativa do Brasil. Brasília, 14 set. 2001. Seção 1E.

. Constituição. Constituição [da] República Federativa do Brasil. Brasília: Senado Federal, 1988.

. Decreto 6571, de 17 de setembro de 2008. Dispõe sobre o atendimento educacional especializado. Disponível em: <www.presidencia.gov.br>. Acesso em: 10/1/2010.

CAIADO, Kátia Regina Moreno; LAPLANE, Adriana Lia Friszman. Tramas e redes na construção de uma política municipal de educação inclusiva. In: BAPTISTA, Cláudio Roberto; JESUS, Denise Meyrelles de. Avanços em políticas de inclusão: o contexto da educação especial no Brasil e em outros países. Porto Alegre: Mediação, 2009. p. 79-90.

JESUS, Denise Meyrelles de. Educação inclusiva: construindo novos caminhos. 2002. 217 f. Relatório (Pós-Doutorado em Educação) - Faculdade de Educação,. Universidade de São Paulo, São Paulo, 2002. 
. Formação continuada: construindo um diálogo entre teoria, prática, pesquisa e educação inclusiva. In: ; BAPTISTA, Claudio Roberto; VICTOR, Sonia Lopes (Org.). Pesquisa e educação especial: mapeando produções. Vitória: EDUFES, 2005. p. 203-218.

PADILHA, A. M. L. Possibilidades de histórias ao contrário: ou como desencaminhar o aluno da classe especial. São Paulo: Plexus, 1997.

PRIETO, Rosângela Gavioli (Org.). Políticas de inclusão escolar no Brasil: descrição e analise de sua implementação em municípios das diferentes regiões. In: REUNIÃO ANUAL DAASSOCIAÇÃO NACIONAL DE PÓS-GRADUAÇÃ̃ E PESQUISA EM EDUCAÇÃO, 27, 2004, Caxambu. Anais... Caxambu, 2004, p. 1-146.

. A educação especial em municípios paulistas: histórias singulares ou tendência unificadora? In: BAPTISTA, Cláudio Roberto; JESUS, Denise Meyrelles de. Avanços em políticas de inclusão: o contexto da educação especial no Brasil e em outros países. Porto Alegre: Mediação, 2009. p. 57-78.

SADER, Emir. Prefácio. In: MÉSZÁROS, István. A educação para além do capital. São Paulo: Boitempo, 2005. p. 15-18.

SANTOS, Boaventura de Souza. A gramática do tempo: para uma nova cultura política. São Paulo: Editora Cortez, 2006.

. Renovar a teoria crítica e reinventar a emancipação social. São Paulo: Boitempo, 2007a.

. Para além do pensamento abissal: das linhas globais a uma ecologia de saberes.

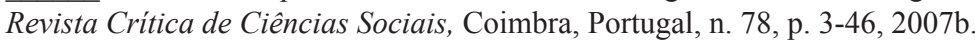

. A filosofia à venda, a douta ignorância e a aposta de Pascal. Revista Crítica de Ciências Sociais, Coimbra, Portugal, n. 80, p. 11-43, mar. 2008.

SILVA, Ana Paula Ferreira da; FREITAS, Marcos Cesar. Escolarização, trabalho e sociabilidade em "situação de risco": apontamentos para uma antropologia da infância e da juventude sob severa pobreza. In: FREITAS, Marcos Cesar (Org.). Desigualdade social e diversidade cultural na infância e na juventude. São Paulo: Cortez Editora, 2006. p. 17-45.

TORRES, Rosa Maria. ONGs e o Banco Mundial: é possível colaborar criticamente? In: TOMMASI, Lívia de; WARDE, Mirian Jorge; HADDAD, Sérgio. (Org.). O Banco Mundial e as politicas educacionais. São Paulo: Cortez, 1998. p. 41-74.

Texto recebido em 09 de dezembro de 2010.

Texto aprovado em 25 de março de 2011. 